\title{
Design Of A-Based Smart Meters To Monitor Electricity Usage In The Household Sector Using Hybrid Particle Swarm Optimization - Neural Network
}

\author{
Muhammad Yusuf Yunus s,1,*, Marhatang $^{\mathrm{a}, 2}$, Andreas Pangkung ${ }^{\mathrm{b}, 3}$, Muhammad Ruswandi Djalal ${ }^{\mathrm{b}, 4}$ \\ ${ }^{a}$ Department of Energy Conversion Engineering, State Polytechnic of Ujung Pandang, Makassar, Indonesia \\ ${ }^{a}$ Department of Energy Generation Engineering, State Polytechnic of Ujung Pandang, Makassar, Indonesia \\ Iyusuf_yunus@poliupg.ac.id, ${ }^{2}$ marhatang@poliupg.ac.id, ${ }^{3}$ andareas_pangkung@poliupg.ac.id, ${ }^{4}$ wandi@poliupg.ac.id
}

Article history:

Received 22 November 2019

Revised 25 December 2018

Accepted 27 July 2019

Keywords:

Smart Meter

Monitoring

Load

Neural Networks

Particle Swarm Optimization
The procedure is training and testing the nerves that will be made. Matlab software has a Neural Network tool, which in this study will be used. Load sampling data is used as input data for neural network training. As output/target load classification is used. Load classification method, which is 1 for TV load classification, 2 for fan load, 3 for iron load, 4 for water pump load, 5 for lamp load, 6 for dispenser load, and 7 for fan iron load combination. The total capacity is six single loads and one combination load. One load combination was chosen because of the combination load characteristics after the fan has features that are not the same as the others. The data sampling of the current of each load will be used as neural network training. Load data used is 30 samples, or for 30 seconds, with every minute the data is taken. From the results of the training, it can be seen that the most significant training error is in the seventh data, namely the identification of the load on the classification of the fan-iron load. This is because the current pattern on the iron and fan with the metal or fan itself has almost the same characteristics. However, for this process, networks will be used, and then the PSO optimization method is used to reduce the error in the next study. From the test results, it is shown that by varying the input current data of each load, the network has been able to identify well, even though in the data classification load 7, the capacity of the ironfan combination still has a significant error. This will be corrected in subsequent studies with Particle Swarm Optimization (PSO) algorithm optimization.

Copyright $\odot 2019$ International Journal of Artificial Intelligence Research. All rights reserved.

\section{Introduction}

Often the consumers of electrical energy, especially household consumers, complain that the electricity bill is too expensive, but not a few consumers are confused because the numbers printed on the electricity bill are also cheap. This is very likely to occur if the system for calculating electricity consumption is still done manually by PLN officers. Because it is done manually, this method has the disadvantage of the possibility of errors [1].

Analog and digital KWH meters that are still used by household consumers can only record electrical energy usage at each hour, and the amount of electricity used is multiplied by the basic electricity tariff (TDL) which is adjusted to the installed power in the housing. On the electricity billing statement, only the nominal amount of the bill must be paid by the consumer without any details that include the use of electronic equipment for one month

In this study, Smart Meters are designed to monitor and identify the use of electrical energy from the use of electronic equipment in consumers' homes in real-time. Consumers can quickly obtain information about how much electricity is used. In this way, consumers can find out and differentiate energy-efficient and energy-efficient electronic equipment so that consumers can 
make sufficient savings. Non Intrusive Load Monitoring (NILM) load monitoring systems [2], where only voltage and current sensors are needed [3-8].

Smart Meter is designed using a hybrid Backpropagation Neural Network and Particle Swarm Optimization. Backpropagation Neural Network is a computational technique based on artificial intelligence that can recognize patterns, classification/identification, prediction, optimization, and function approaches. The ability to backpropagation neural networks in recognizing patterns and identification can solve problems in monitoring and identifying the use of electrical energy with accurate results.

\section{Research Methods}

The design of the NILM-based smart meter design here includes hardware and software design. Where to design the hardware consists of several supporting components such as starting from reading data or measuring current in each household electrical equipment using a current sensor, then the measurement results are used for signal conditioning, and the results are converted to digital quantities using the Arduino Uno component. As well as for software design in this study using a hybrid combination of BPNN and PSO so that this monitoring will be observed in realtime.

In this study, the use of the Neural Network algorithm is used as a load identification method. In its application, there are several procedures/steps taken to make a nerve that can recognize and decide the action. The process is training and testing the nerves that will be made. Matlab software has a Neural Network tool, which in this study will be used. Load sampling data in the table for each pattern will be used as input data for neural network training. As the output / target, the table is used to identify the load.

\section{Results \& Discussions}

In this study conducted using household electrical loads, such as televisions, lamps, water pumps, irons, fans, and dispensers. The current characteristics of each load are shown in the following figure. The total capacity is six single loads and one combination load. One load combination was chosen because of the combination load characteristics after the fan has features that are not the same as the others. The data sampling of the current of each load will be used as neural network training. Load data used is 30 samples, or for 30 seconds, with every minute the data is taken. Table 1 shows the results of sampling the load for 30 seconds. Table 2 shows the load classification, which is 1 for TV load classification, 2 for fan load, 3 for iron load, 4 for water pump load, 5 for lamp load, 6 for dispenser load, and 7 for fan iron load combination.

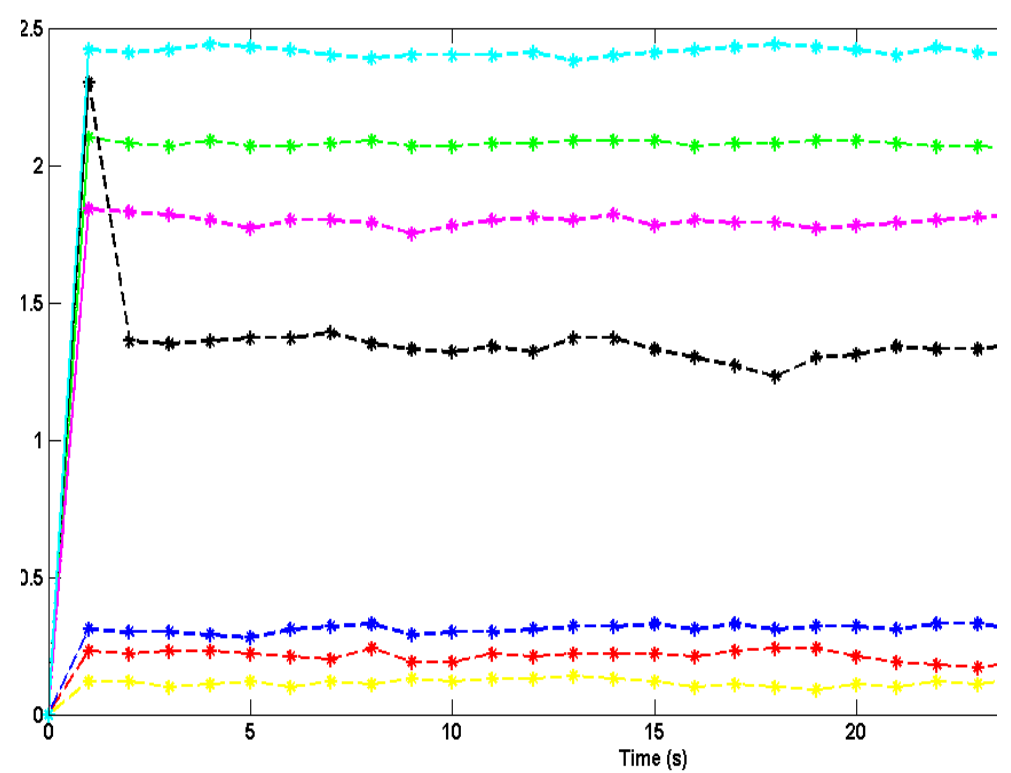

Fig 3. Current Characteristics of each Load 
Table 1. Load Sampling Results

\begin{tabular}{|c|c|c|c|c|c|c|c|}
\hline Data & TV & Fan & Iron & Pump & Lamp & Dispenser & Iron-Fan \\
\hline 1 & 0.23 & 0.31 & 2.1 & 2.3 & 0.12 & 1.84 & 2.42 \\
\hline 2 & 0.22 & 0.3 & 2.08 & 1.36 & 0.12 & 1.83 & 2.41 \\
\hline 3 & 0.23 & 0.3 & 2.07 & 1.35 & 0.1 & 1.82 & 2.42 \\
\hline 4 & 0.23 & 0.29 & 2.09 & 1.36 & 0.11 & 1.8 & 2.44 \\
\hline 5 & 0.22 & 0.28 & 2.07 & 1.37 & 0.12 & 1.77 & 2.43 \\
\hline 6 & 0.21 & 0.31 & 2.07 & 1.37 & 0.1 & 1.8 & 2.42 \\
\hline 7 & 0.2 & 0.32 & 2.08 & 1.39 & 0.12 & 1.8 & 2.4 \\
\hline 8 & 0.24 & 0.33 & 2.09 & 1.35 & 0.11 & 1.79 & 2.39 \\
\hline 9 & 0.19 & 0.29 & 2.07 & 1.33 & 0.13 & 1.75 & 2.4 \\
\hline 10 & 0.19 & 0.3 & 2.07 & 1.32 & 0.12 & 1.78 & 2.4 \\
\hline 11 & 0.22 & 0.3 & 2.08 & 1.34 & 0.13 & 1.8 & 2.4 \\
\hline 12 & 0.21 & 0.31 & 2.08 & 1.32 & 0.13 & 1.81 & 2.41 \\
\hline 13 & 0.22 & 0.32 & 2.09 & 1.37 & 0.14 & 1.8 & 2.38 \\
\hline 14 & 0.22 & 0.32 & 2.09 & 1.37 & 0.13 & 1.82 & 2.4 \\
\hline 15 & 0.22 & 0.33 & 2.09 & 1.33 & 0.12 & 1.78 & 2.41 \\
\hline 16 & 0.21 & 0.31 & 2.07 & 1.3 & 0.1 & 1.8 & 2.42 \\
\hline 17 & 0.23 & 0.33 & 2.08 & 1.27 & 0.11 & 1.79 & 2.43 \\
\hline 18 & 0.24 & 0.31 & 2.08 & 1.23 & 0.1 & 1.79 & 2.44 \\
\hline 19 & 0.24 & 0.32 & 2.09 & 1.3 & 0.09 & 1.77 & 2.43 \\
\hline 20 & 0.21 & 0.32 & 2.09 & 1.31 & 0.11 & 1.78 & 2.42 \\
\hline 21 & 0.19 & 0.31 & 2.08 & 1.34 & 0.1 & 1.79 & 2.4 \\
\hline 22 & 0.18 & 0.33 & 2.07 & 1.33 & 0.12 & 1.8 & 2.43 \\
\hline 23 & 0.17 & 0.33 & 2.07 & 1.33 & 0.11 & 1.81 & 2.41 \\
\hline 24 & 0.19 & 0.31 & 2.06 & 1.35 & 0.13 & 1.82 & 2.4 \\
\hline 25 & 0.2 & 0.32 & 2.09 & 1.3 & 0.12 & 1.82 & 2.4 \\
\hline 26 & 0.17 & 0.32 & 2.1 & 1.3 & 0.11 & 1.83 & 2.4 \\
\hline 27 & 0.19 & 0.3 & 2.09 & 1.3 & 0.1 & 1.83 & 2.41 \\
\hline 28 & 0.19 & 0.3 & 2.08 & 1.29 & 0.12 & 1.82 & 2.42 \\
\hline 29 & 0.2 & 0.3 & 2.08 & 1.28 & 0.13 & 1.82 & 2.42 \\
\hline 30 & 0.21 & 0.31 & 2.09 & 1.28 & 0.12 & 1.8 & 2.4 \\
\hline
\end{tabular}

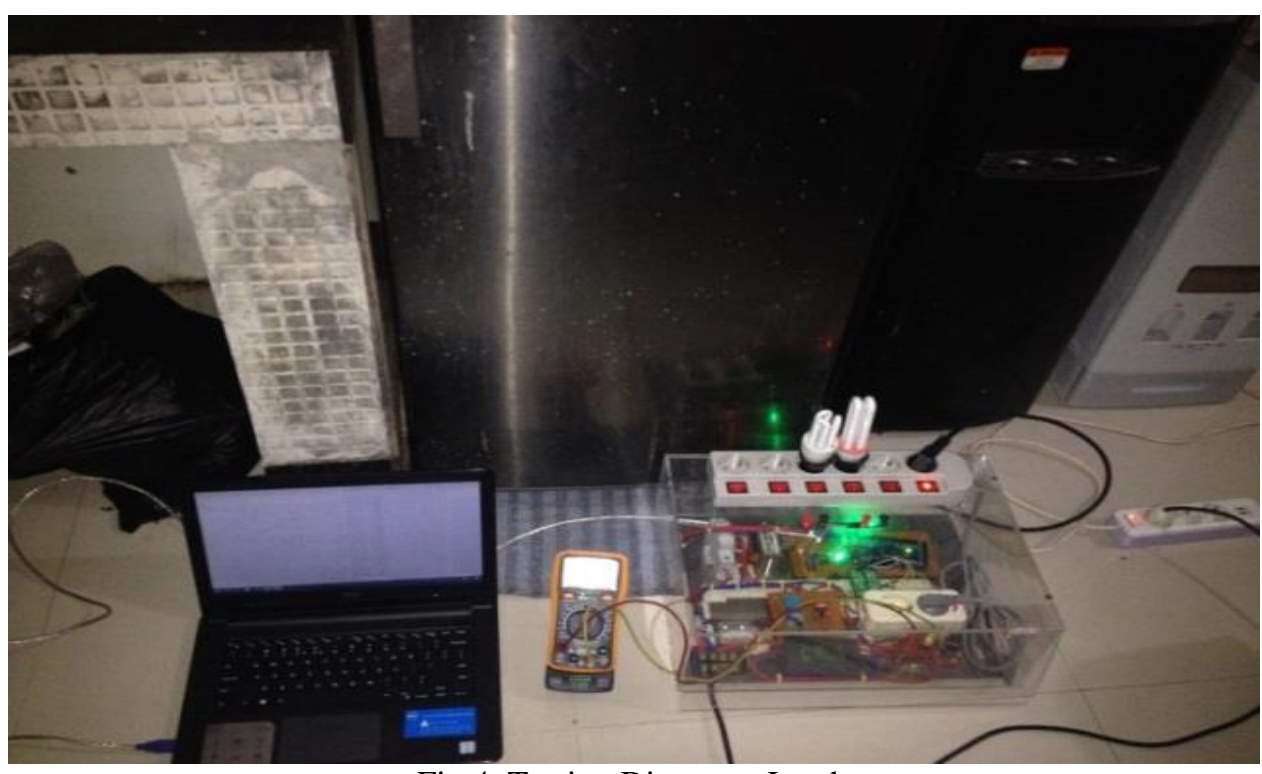

Fig 4. Testing Dispenser Loads 
Table 2. Load Classification

\begin{tabular}{ccc}
\hline No & Loads & Classification \\
\hline 1 & TV & 1 \\
2 & Fan & 2 \\
3 & Iron & 3 \\
4 & Pump & 4 \\
5 & Light & 5 \\
6 & Dispenser & 6 \\
7 & Iron + Fan & 7 \\
\hline
\end{tabular}

\section{B. Software Testing}

In this study, the use of the Neural Network algorithm is used as a load identification method. In its application, there are several procedures/steps taken to make a nerve that can recognize and decide the action. The process is training and testing the nerves that will be made. Matlab software has a Neural Network tool [9], which in this study will be used. The sampling data load in table 5.1 for each pattern will be used as input data for neural network training. As the output / target, table 5.2 is used to identify the load. The following will explain some steps or procedures in making a nerve to determine the burden in this study. Artificial neural network training aims to recognize load patterns $[10,11]$, the first step is to enter current input data in MatLab, by creating an input variable in the workspace column, as well as output/target data, shown in the figure. The next procedure for network training that has been made, this procedure will take time, because it takes several practice or experiments in conducting training until the error is small. The following is the overall network appearance that will be made.

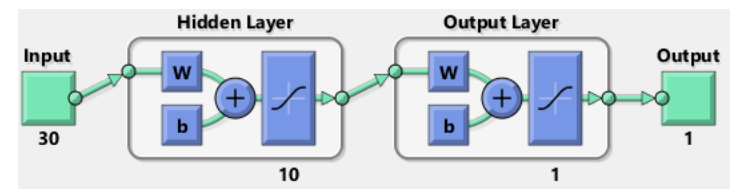

Fig 5. Neural network Design

From the results of the training, it can be seen that the most prominent training error is in the seventh data, namely the identification of the load on the classification of the fan-iron load. This is because the current pattern on the iron and fan with the metal or fan itself has almost the same characteristics. However, for this process, networks will be used, and then the PSO optimization method is used to reduce the error in the next study. The neural network that has been created is then modeled so that the system response can be seen in recognizing load patterns or load identification. The results of neural networks modeling are shown in the following figure.

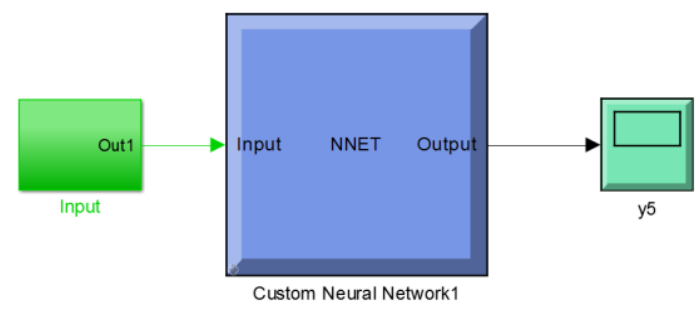

Fig 6. Artificial Neural Network Modeling Design

Next is to create a block for current data input, shown in the following figure. 


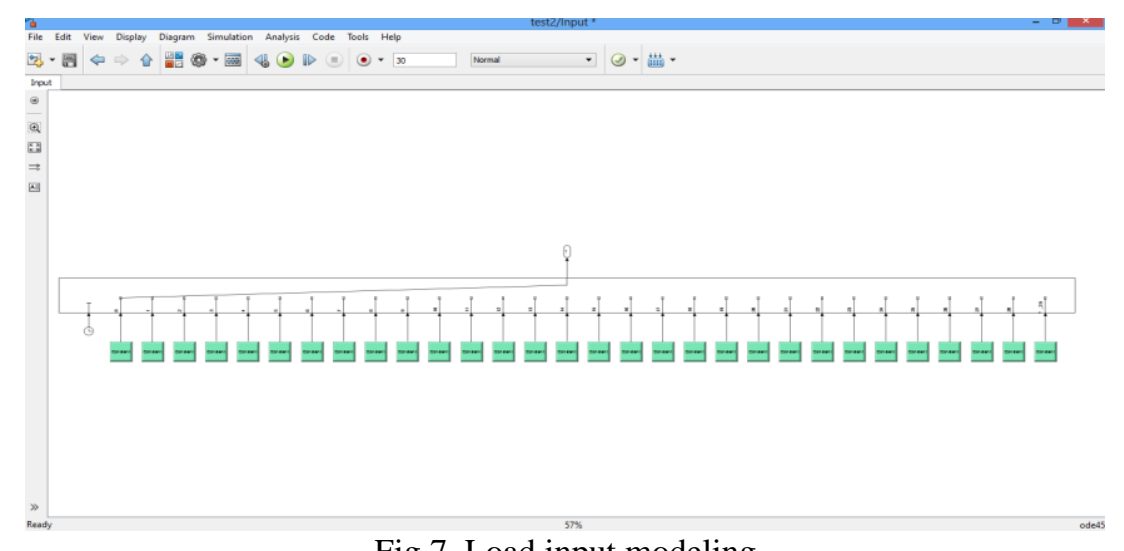

Fig 7. Load input modeling

The following figure shows the sub-sections of neural networks that have been created, with two layers.

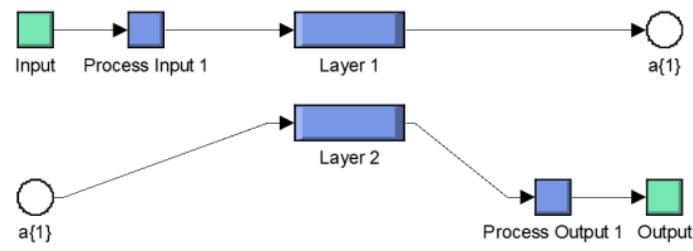

Fig 8. Layer Neural Network Modeling

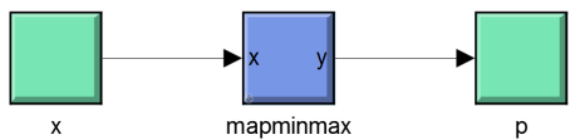

Fig 9. Custom Neural Process Input Design

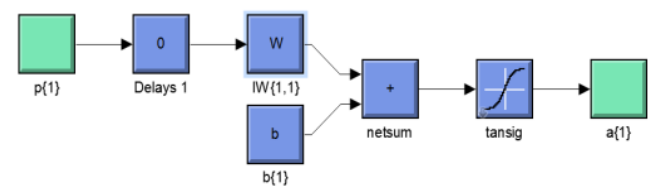

Fig 10. Custom Neural Network Layer 1

After the modeling is made on Simulink, the next test is the modeling that has been made.

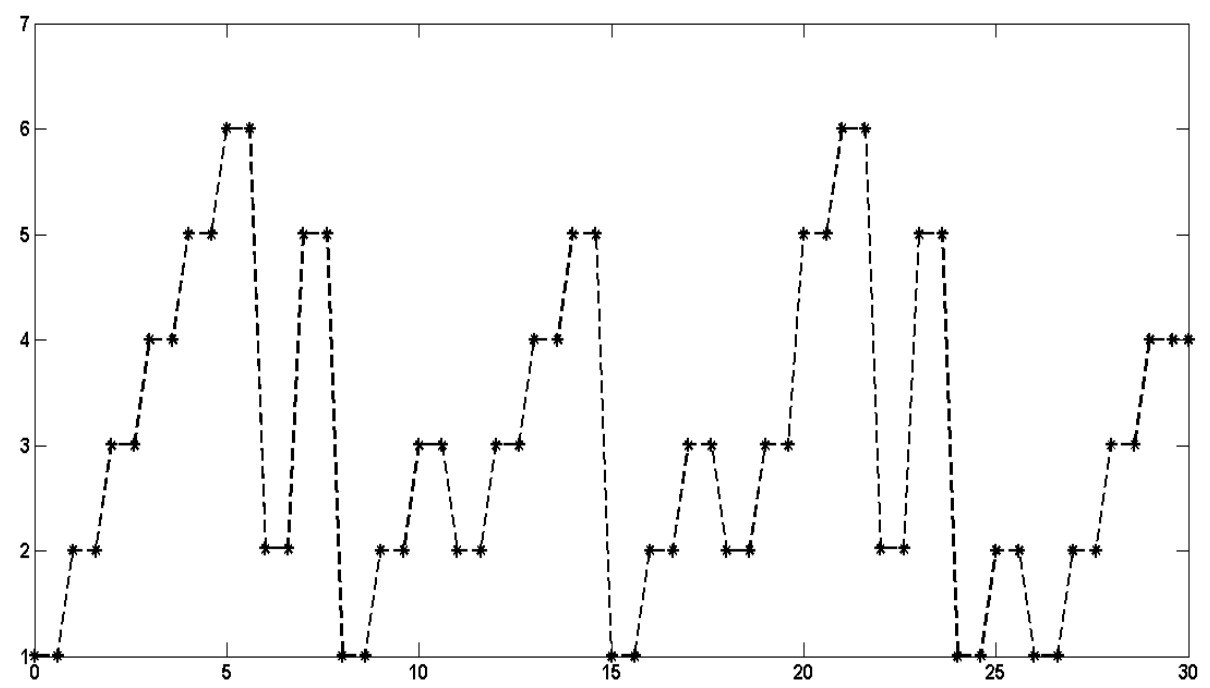

Fig 11. Load classification response 


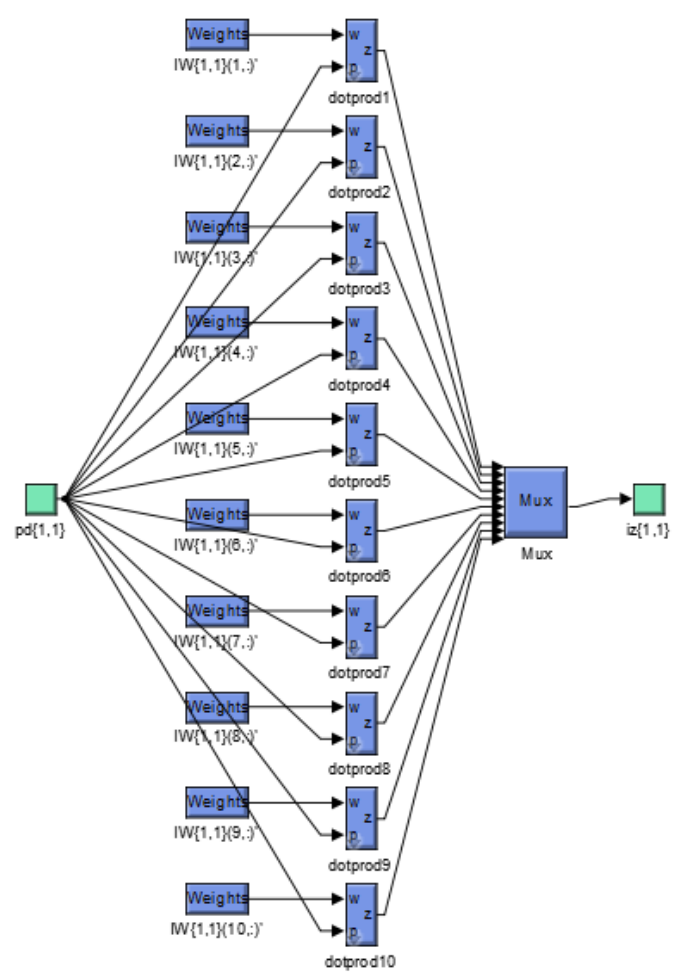

Fig 12. Custom Neural Network Layer 1 Weight

To display load identification information on the smart meter, in the tool panel, an LCD screen is added to display load identification information. The following is shown the identification results using LabView and LCD. The display of electrical energy monitoring in LabVIEW consists of several menus, including the Home and Monitoring menus.

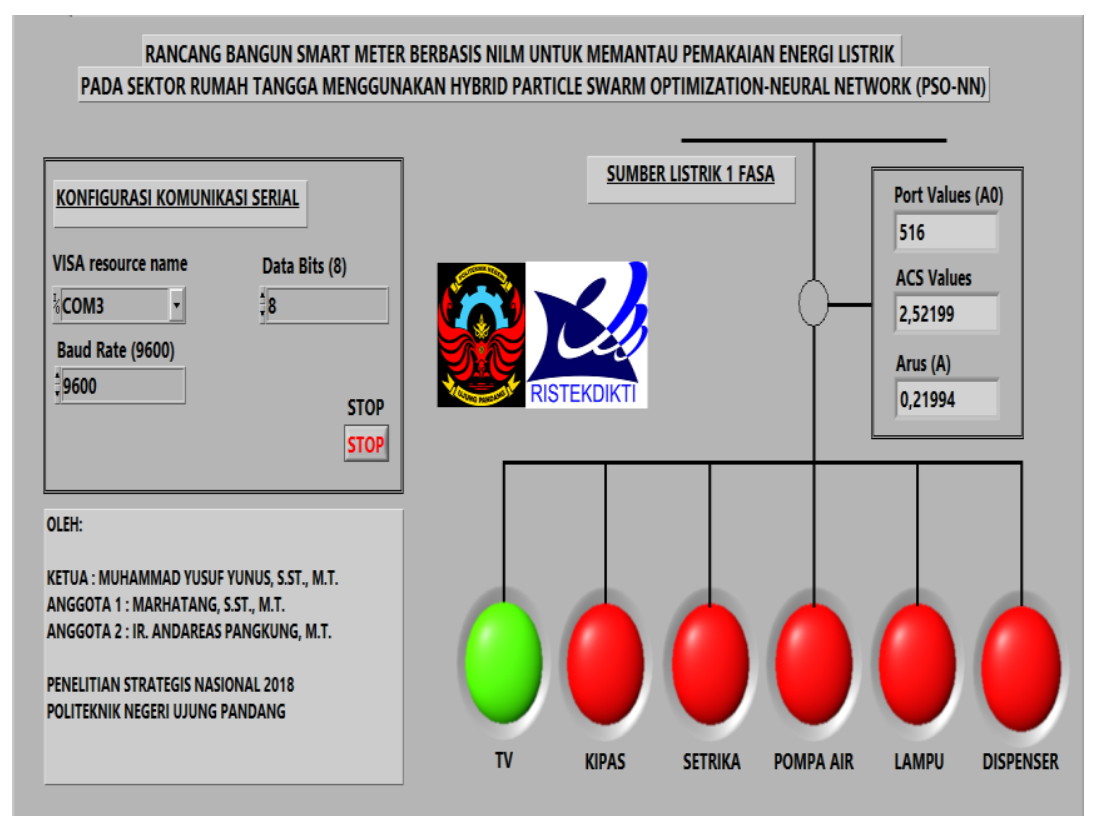

Fig 13. Display of LabView Identification of TV Expenses 


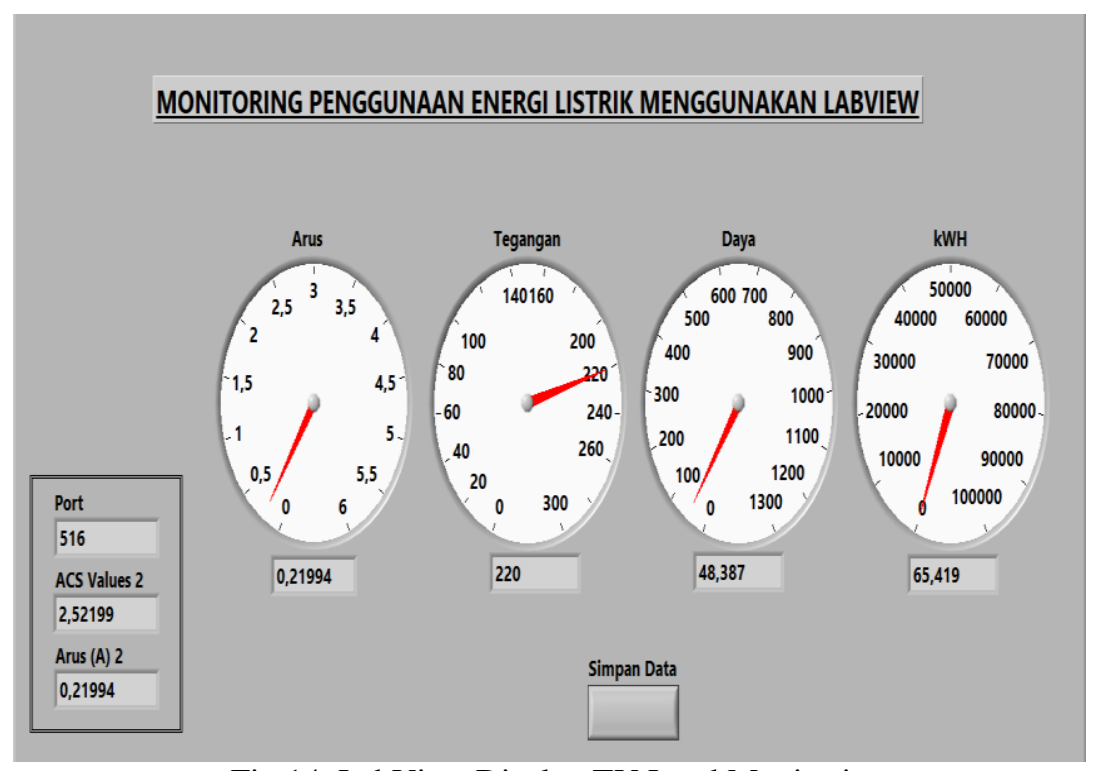

Fig 14. LabView Display TV Load Monitoring

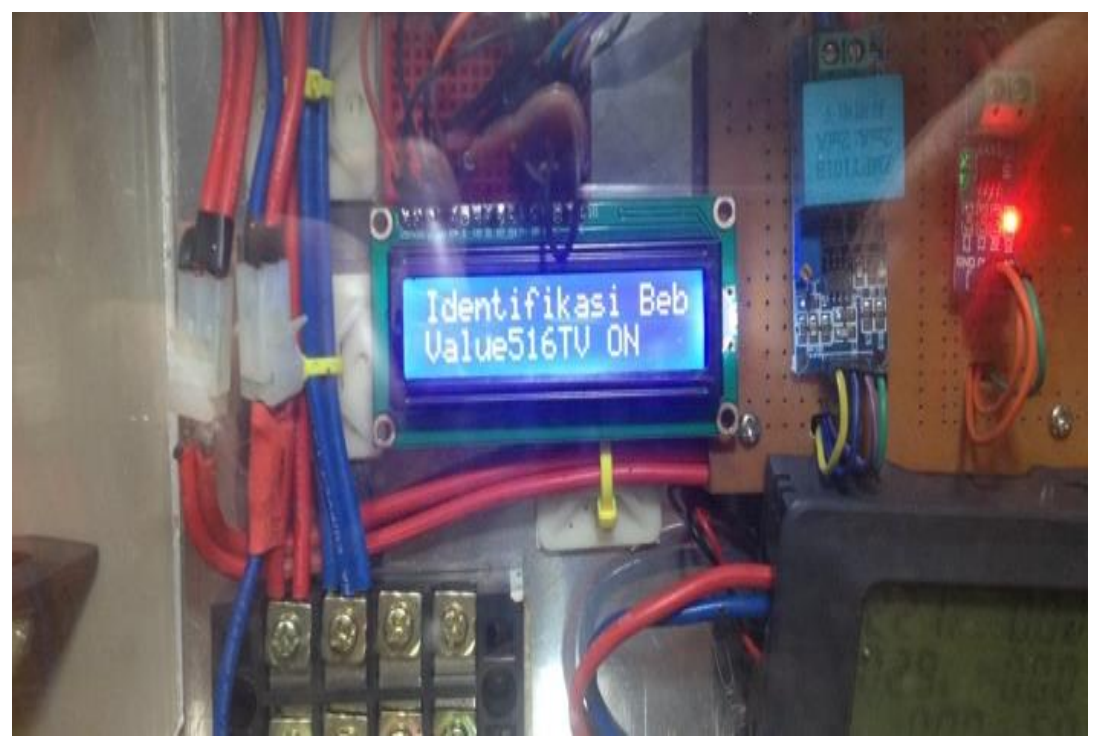

Fig 15. TV Display LCD Load

Next, load identification using the neural network - particle swarm optimization (PSO) algorithm optimization. From the results of the identification of the load obtained a relatively large error. Here are the parameters of the PSO algorithm in performing neural network optimization and load identification.

Table 3. PSO Parameter

\begin{tabular}{ccc}
\hline No & Parameter & Value \\
\hline 1 & Upper Limit & $-5-$ \\
2 & Lower Limit & 5 \\
3 & Max Iteration & 50 \\
4 & Population Size & 50 \\
5 & Inertia Weight & 1 \\
6 & Inertia Weight Damping Ratio & 0,99 \\
7 & Personal Learning Coefficient & 1,5 \\
8 & Global Learning Coefficient & 2 \\
\hline
\end{tabular}

Here are the results of the PSO algorithm optimization, which shows the computation process for 50 iterations to find the optimal value. From the results showed that iteration 47 obtained the most optimal cost. 


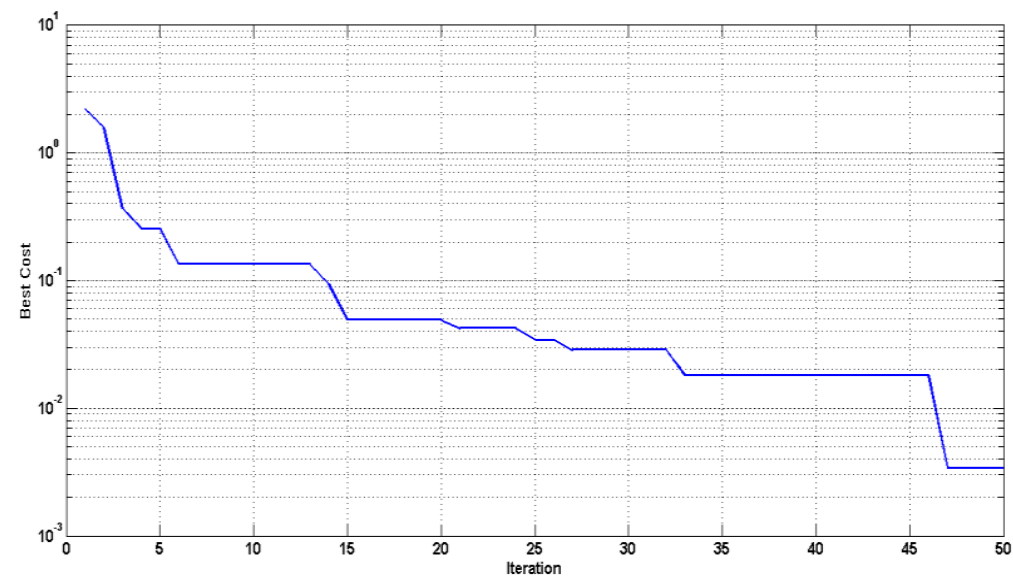

Fig 16. PSO algorithm convergence graph

From these results, the identification results are obtained as follows.

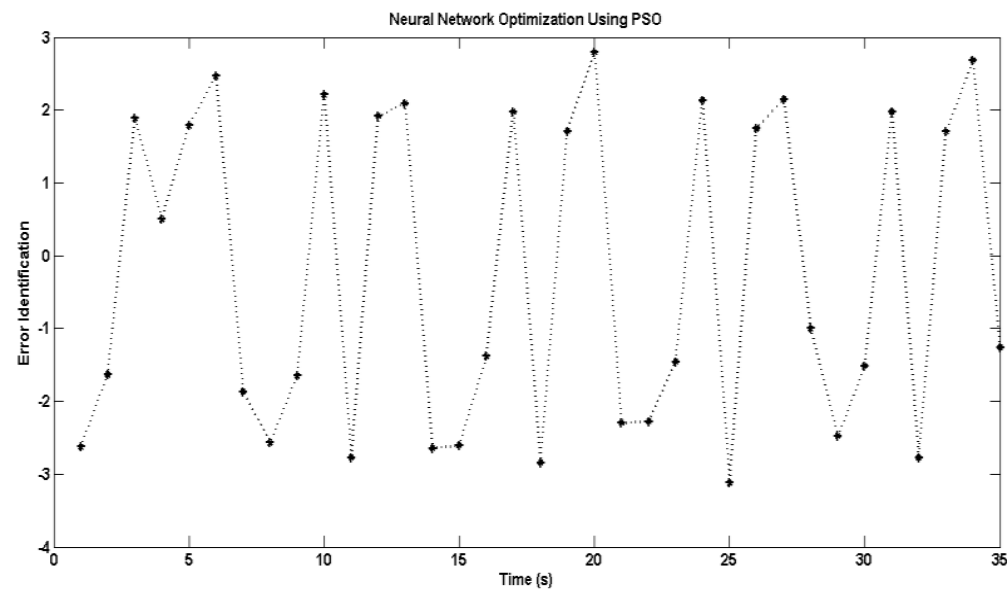

Fig 17. Graph of load identification errors using neural network algorithms optimized by PSO

From the results, it is shown that by varying the input current data of each load, the network has been able to identify well, even though in the data classification load 7, the amount of the iron-fan combination still has a significant error.

\section{Conclusion}

From the results that have been achieved, monitoring and identification of electricity load usage have been well done. Load monitoring is done by observing the current, voltage, and power parameters. And identification of load usage to classify the types of loads that are being used using neural network algorithms and particle swarm optimization. And the addition of an information system with an LCD that displays load identification information used. From the results of load identification using the neural network algorithm, the most significant identification error is found on the load of fan iron which is equal to $71.15 \%$, while using the most significant identification error PSO is at the pump load of $3.1 \%$.

\section{References}

[1] H. Koko, "Desain Smart Meter Untuk Memantau Dan Identifikasi Pemakaian Energi Listrik Pada Sektor Rumah Tangga Menggunakan Backpropagation Neural Network," ITS Surabaya, 2015.

[2] G. W. Hart, "Nonintrusive Appliance Load Monitoring," presented at the Proceedings IEEE, 1992.

[3] I. E. L. J. G. Roos, E. C. Lane, and G. P. Hanche "Using neural networks for non-intrusive monitoring of industrial electrical loads," presented at the Proceedings of IEEE Instrumentation and Measurement Technology Conference, 1994.

[4] K. L. C. Laughman, R. Cox, S. Shaw, S. B. Leeb, L. Norford, and P. Armstrong, "Power Signature 
Analysis," presented at the IEEE Power \& Energy Magazine, 2003.

[5] T. R. f. D. o. E. C. C. Energy Consumption in the United Kingdom, "Energy Consumption in the United Kingdom, Technical Report for Department of Energy \& Climate Change " 2010.

[6] a. L. S. J. Utley, "Domestic Energy Fact File," Technical Report for Building Research Establishment: Garston, UK., 2008.

[7] S. K. K. N. Jian Liang, Gail Kendall, and John W. M. Cheng, "Load Signature Study—Part I: Basic Concept, Structure, and Methodology," presented at the IEEE Transactions On Power Delivery, 2010.

[8] K. A. D. K.E Martinez, and J.A Laitner "Advanced Metering Initiatives and Residential Feedback Programs: A Meta-Review for Households electricity-saving Opportunities," Technical Report E105 for American Council for an Energy-Efficient Economy (ACEE), USA., 2010.

[9] S. Kusumadewi, "Membangun Jaringan Syaraf Tiguan Menggunakan MATLAB \& EXCEL LINK," Graha Ilmu, 2004.

[10] M. H. Purnomo, dan Kurniawan, A, "Supervised Neural Networks dan Aplikasinya," Graha Ilmu, 2006.

[11] Y.-Y. Hong and J.-H. Chou, "Nonintrusive energy monitoring for microgrids using hybrid selforganizing feature-mapping networks," Energies, vol. 5, pp. 2578-2593, 2012. 